\section{Internal Validation of Subjective Bayesian Model of The Occurrence of Alveolar Osteitis Cases, Generated by Expert in Kinshasa Hospital/DRC}

\section{Abstract}

Objective: To valid an Internal Model Subjective of Bayer by the case of alveolar osteitis generated by the Experts.

Methods: The qualitative method was carried out under form of integration group, with had eight experts. The selection criteria of experts were to be a professor at the faculty of Dental medicine, a master's degree in oral surgery, dentistry, periodontology, prosthesis and to be dental doctor with more than 20 years of occupation. Elaboration of SBM was carried out by three steps such as determination of a prior probability of quotient (APRIQ), determination of the likelihood ratio (LHR) and Determination of a posteriori probability quotient (APPQ. And SBM was validated in three stages: determination of the agreement degree of intra and inter experts; of Cut off point (COP) and Internal validation. The agreement degree of intra and inter expert was determined by kappa statistics.

Results: Seven risks factors such as F1=bad oral and dental hygiene, F2=Systemic diseases, F3=pre-existent infections, F4=Preoperative Infection, F5=lack of asepsis, F6=unexperienced practitioner and F7=post-operative infection was identified. A prior probability of quotient was 0.21 . Likelihood ratio (LHR) of 7 independents factors are $L H R=F_{1}=3 ; F_{2}=1.5 ; F_{3}=4 ; F_{4}=1.5 ; F_{5}=1.3 ; F_{6}=1.5$ and $F_{7}=3$ and $L H R=F_{11}=0.28 ; F_{2=} 0.25 ; F_{3=} 0.16 ; F_{4=} 0.4 ; F_{5=} 0.75 ; F_{6=} 0.33$ and $F_{7=} 0.14$.

Conclusion: The Poor oral hygiene LHR3; post-operative infections LHR3, preoperative infections LHR4, were the most important identified factors predictive of occurrence of $A O$ in our 8 dental hospital of D. R. Congo/Kinshasa city. The corrected of these three factors can contribute to reduce the frequency of that pathology in Kinshasa population.

Keywords: Alveolar osteitis; Internal validation; Subjective bayer's model
Muyembi MPP, Sekele JP' , Kashiama B', Bobe $\mathrm{P}^{1}$, Kalala EM${ }^{1}$, Nyimi Bushabu F1,3, Dzaringa $\mathrm{T}^{1}$, Tshilela $\mathrm{M}^{3}$, Duan Feng $\mathrm{F}^{3}$, Munyanga $\mathrm{S}^{4}$ and Mantshumba MA ${ }^{1}$

1 Department of Stomatology, University of Kinshasa, Affiliated Hospital of Kinshasa University, Kinshasa, D. R. Congo

2 Department of Medical and Food Anthropology, University of Kinshasa, Administrative and Political, Kinshasa, D. R. Congo

3 Department of Oral and Maxillofacial Surgery, Second Affiliated Hospital of Jiamusi University, Jiamusi, China

4 Department of Statistics, School of Public Health, University of Kinshasa, Kinshasa, D. R. Congo

Corresponding author:

Muinaminayi Pierre Muyembi

” pierremuyembim@gmail.com

Internal Validation of Subjective Bayesian Model of The Occurrence of Alveolar Osteitis Cases, Generated by Expert in Kinshasa Hospital/DRC.

Tel: 00243819072550

Citation: Muyembi MP, Sekele JP, Kashiama $B$, et al. Internal Validation of Subjective Bayesian Model of The Occurrence of Alveolar Osteitis Cases, Generated by Expert in Kinshasa Hospital/DRC. J Orthod Endod. 2016, 2:3.
An operations of oral surgery is relate primarily on the teeth, soft tissue and bone. Despite the advance of restorative dentistry and prosthetic rehabilitation techniques as well as periodontics, the dental extractions still a very common surgical practice in Africa $[1,2]$.

In certain conditions, despite the perfect knowledge of the practitioner and mastering of the surgical plan, the surgical operations can be delicate and difficult to predict some complications during or after surgery. In the postoperative, the most frequent complications of dental extraction are inflammatory or infectious such as alveolar osteitis (AO), which 
includes the dry and suppurative alveolitis [3-5].

This study was initiated to identify 7 groups' factors of occurrence of $A O$ by a mathematical model of Bayer, which is based on the opinions of experts who use the qualitative data [6-8]. Clinical interest will be to help the clinicians use a mathematical model for the 7 predictive factors of AO such as non-modified factors (age and gender) and modified factors (poor oral hygiene, systematic diseases, infections, aseptic technique, lack of practitioner, the postoperative infections [5, 9-12]. However, it is possible to prevent the occurrence of $A O$ in patients with the modified risk factors $[3,5,12]$.

In some development countries, the dental extractions are often followed by postoperative complications, which result as a high morbidity of the patients $[1,2,13,14]$. However, in Democratic Republic of Congo, no study found from the literature have been initiated on the AO by using a mathematical model. From 2011, Muyembi et al. [11] conducted a descriptive prospective and preventive study of $A O$ in the Affiliated Hospital of Kinshasa University and the result of pattern occurrence of $A O$ found was $13.3 \%$. This is a sign that the AO relates are not only concern to the less educated person, but also in all class or category of the persons such as university workers, graduates or students of Kinshasa University, with morbid consequences that flow from it $[11,14]$.

Thus, view the increase frequency postoperative of $\mathrm{AO}$ and its consequences of economic and social disability of the patient due days work in the development countries and view the lacking information and training of the population of the Democratic Republic of the Congo for the good oral health, due to the decrease of dental surgeons in our country (one surgeons/4.865 population in Kinshasa Capital where there is a large population, estimated at 10,000,000 people); we have been asked to conduct a qualitative study on the determinants of the occurrence of $A O$ in the eight major Dental hospitals of Kinshasa city [14-19].

The results of the mathematical model built will used for an elaboration of tree clinical decision, and will help us to reflect the prediction software of AO. Then, on the basis of this model, we will do an algorithm treatment of all oral diseases post-dental extraction.

This study aims was to identify the occurrence factors of $A O$ in Kinshasa population treated at 8 major dental Hospital and will make the recommendations for to improve the management of dental extraction of numerous service of stomatology in Democratic Republic of Congo in general, and particular to Kinshasa Capital.

\section{Materials and Methods}

This study used a qualitative method under form as a nominal group, which is based on Bayesian statistics and adapted from work of Gustafson [20, 21]. The choice of this method is justified by the fact that these statistics are help to use the opinions, the subjective elements provided by experts for to generate the statistics on the basis of the evidence $[8,22,23]$. The qualitative method was carried out under form of integration group, with had eight experts. It has helped to identify the factor can establish the occurrence of $\mathrm{AO}$ in patients who dental extractions were mad from 8 dental clinics hospital of Kinshasa (D. R. Congo).

It was conducted by six steps: (1) Selection of experts; (2) Interview of experts (search of a consensus on the definition of variables and elaboration a provisional list of predictors factors); (3) Training of experts; (4) Establishment list of predictive factors; (5) Regrouping of independent factors and (6) Elaboration model. The selection criteria of experts were to be a professor at the faculty of Dental medicine, a master's degree in oral surgery, dentistry, periodontology, prosthesis and to be dental doctor with more than 20 years of occupation. All have the skills and knowledge of $A O$, and be available during the period of our study. Interview of experts by Brainstorming followed by technique of nominal group, have been help resulted an elaboration of provisional list factors of $\mathrm{AO}$; used for an elaboration of the Subjective Bayesian model (SBM).

Elaboration of SBM was carried out by three steps: determination of a prior probability of quotient (APRIQ), determination of the likelihood ratio (LHR) and Determination of a posteriori probability quotient (APPQ)

a) The prior probability of quotient (APRIQ) was established from an arithmetic mean of the different estimations of expert on the probability of occurrence of $A O)$. $P(A O)$ compared with the probability of non-occurrence of $\mathrm{AO} \mathrm{P}(\overline{\mathrm{AO}})$.

The probability of $\mathrm{AO} ; \mathrm{P}(\mathrm{AO})$ was obtained by asking this question to experts: "On 10 patients treated in your department, how much have been developed the AO?" The probability of occurrence of $A O, P(A O)$ was obtained by the sum of the frequencies estimated by 8 experts. The probability of non-occurrence of $A O, P(\overline{\mathrm{AO}})$ have been deducted according to the law of the probability distribution, $\mathrm{P}(\overline{\mathrm{AO}})=1-\mathrm{P}(\mathrm{AO})$.

$$
\mathrm{APRIQ}=\frac{\mathrm{P}(\mathrm{AO})}{\mathrm{P}(\overline{\mathrm{AO}})}=\frac{\mathrm{P}(\mathrm{AO})}{1-\mathrm{P}(\mathrm{AO})}
$$

b) The determination of the likelihood ratio (LHR) for each independent factor identified by experts $\left(F_{i}, i=1, \ldots ., F 7\right.$ and $\left(F_{i}\right.$ $i=1, \ldots . ., 7$ ), likelihood ratio (LHR ) help to establish an impact of each factor on the studied event. LHR $>1$, the factor increased the occurrence of $A O$; $L H R<1$, the factor decreases the occurrence of $A O$, and negative if $L H R=1$

C) Determination of a posteriori probability quotient (APPQ): The $A P P Q$ is obtained by multiplying the different likelihood ratios by the a priori probability quotient (APRIQ). APPQ $=L H R \times A P R I Q$.

d) Probability occurrence of O.A: $P=\frac{A P P Q}{1+A P P Q}$ and SBM was

validated in three stages: 1 ) Determination of the agreement degree of intra and inter experts; 2) Determination of Cut off point (COP); 3) Internal validation.

Establishment of an agreement degree of intra and inter experts was performed by 8 experts who each built 5 cases hypothesis, either 40 cases of $\mathrm{AO}$, with the presence of this or that factors 
can contributed on the occurrence of $A O$ at twice individually. And determination of occurrence of $A O$ in the plenary. The agreement degree of intra and inter expert was determined by kappa statistics using this formula:

$\mathrm{K}=\frac{\mathrm{P}_{\mathrm{a}}-\mathrm{P}_{\mathrm{e}}}{1-\mathrm{P}_{\mathrm{e}}}$

$P_{a=}$ Agreement probability expected

$\mathrm{P}_{\mathrm{o}=}$ Agreement probability observed

$\mathrm{K}=\mathrm{A}$ value between 0 and 1 . If $\mathrm{K}<0.4$ low agreement; $0.4 \leq \mathrm{K}$ 0.6 means agreement; $0.6 \leq \mathrm{K}<0.8$ good agreement; $\mathrm{K} \geq 0.8$ excellent agreement

This internal validation of the subjective Bayesian model (SMB) will be determined from the case of alveolar osteitis on which the experts shall reached consensus on the occurrence or non-occurrence of $\mathrm{AO}$. Then parameters such as sensitivity (Sy), specificity (Sp), positive predictive value (PPV), negative predictive value (NPV) and overall efficiency value (OEV) will be evaluated [10].

Determination of COP will be calculate by these parameters for each value between 0.1 and 0.9 . The COP was determined and corresponds to the value of SBM that has a higher sensitivity and greater specificity.

\section{Results}

\section{Factors identified}

Eight experts were included in study and the unmodifiable factors such as gender and age (10 to 80 years) wasn't been taken account. Seven independent modified factors and exclusive were obtained by the technique of Nominal groups techniques are shown in Table 1.

\section{Elaboration of SBM}

Determination of a prior probability of quotient (APRIQ): From clinical experience of experts, an average number of patients treated in 8 dental clinics hospitals and developed an AO on 10 cases were established. The mean number of patients who did not developed an $A O$ was deduced. The occurrence probability of $A O$ in patient $P(A O)$ was estimated at 0.175 and its complementary probability $\mathrm{P}(\mathrm{OA})$ was deduced at 0.825 .

$\mathrm{APRIQ}=\frac{\mathrm{P}(\mathrm{AO})}{\mathrm{P}(\overline{\mathrm{AO}})}=\frac{0.175}{0.325}=0.21$

The value of AFRIQ was less than 1, thus prediction of experts showed that a patient has less chance to develop an AO.

The determination of the likelihood ratio (LHR) of independents factors: Different likelihoods ration of 7 factors generated by the experts are: $L H R=F_{1}=3 ; F_{2}=1.5 ; F_{3}=4 ; F_{4}=1.5 ; F_{5}=1.3 ; F_{6}=1.5$ and $F_{7}$

$=3 ; \quad L H R=F_{1}=0.28 ; F_{2}=0.25 ; F_{3}=0.16 ; F_{4}=0.4 ; F_{5}=0.75 ; F_{6}=0.33$ and

$$
\overline{\mathrm{F}}_{7}=0.14 ; \quad \mathrm{LHR}=\frac{\mathrm{P}(\mathrm{F} 1 / \mathrm{AOA})}{\mathrm{P}(\mathrm{F} 1 / \overline{\mathrm{AO}})} \times \rightarrow \frac{\mathrm{P}(\mathrm{F} 7 / \mathrm{AO})}{\mathrm{P}(\mathrm{F} 7 / \overline{\mathrm{AO}})} ; \mathrm{LHR}=3 \times 1.5
$$

Table 1: Independent 7 factors and exclusive obtained by nominal group technique.

\begin{tabular}{|c|c|}
\hline Factors (F) & Regroupment \\
\hline $\begin{array}{l}\text { F1: Bad oral and } \\
\text { dental hygiene }\end{array}$ & $\begin{array}{l}\text { - Poor or bad oral hygiene state } \\
\text { - Smoker } \\
\text { - Environmental factors, economic and } \\
\text { socio-geographical }\end{array}$ \\
\hline $\begin{array}{l}\text { F2: Systemic } \\
\text { diseases leading } \\
\text { to the deficiency } \\
\text { of immunity }\end{array}$ & $\begin{array}{l}\text { - Immune deficiency (anemia, diabetes, } \\
\text { AIDS, Avitaminosis) }\end{array}$ \\
\hline $\begin{array}{l}\text { F3: Pre-existent } \\
\text { infections }\end{array}$ & $\begin{array}{l}\text { - Apical periodontitis acute with abscess } \\
\text { - } \text { granuloma periodontitis chronic with } \\
\text { - Periodontal infection of vicinity } \\
\text { - Hot tooth extraction } \\
\text { - The aero-anaerobic microorganisms } \\
\text { - Multifactorial } \\
\text { - Healthy factors }\end{array}$ \\
\hline $\begin{array}{l}\text { F4: Preoperative } \\
\text { Infection }\end{array}$ & $\begin{array}{l}\text { - Alveolar curettage } \\
\text { - Alveolar infection } \\
\text { - Pre-operative infection by bacteria }\end{array}$ \\
\hline $\begin{array}{l}\text { F5: Lack of } \\
\text { asepsis }\end{array}$ & - No asepsis (operator-materials) \\
\hline $\begin{array}{l}\text { F6: } \\
\text { Unexperienced } \\
\text { practitioner }\end{array}$ & $\begin{array}{l}\text { - } \text { Traumatic extraction } \\
\text { - } \text { - } \text { Extraction Difficulty } \\
\text { - } \text { Residuals fragments (bone, dental, } \\
\text { - } \quad \text { Thirtars } \\
\text { - } \text { teeth } \\
\text { - } \text { Bad used xylocaine anesthesia with } \\
\text { - } \text { Singular extraction than numerous } \\
\text { - } \text { Vascular trauma } \\
\text { - Bad design of mucoperiosteal flap } \\
\text { - Bad suture post-operative }\end{array}$ \\
\hline $\begin{array}{l}\text { F7: Post- } \\
\text { operative } \\
\text { infection }\end{array}$ & $\begin{array}{l}\text { - Intensive rinsing the wound } \\
\text { - Move out the alveolar clot } \\
\text { Postoperative Mouth wash by Nacl } \\
\text { solution } \\
\text { - Infection of postoperative wound by } \\
\text { bacteria ,biofilm }\end{array}$ \\
\hline
\end{tabular}

$\times 4 \times 1.5 \times 1.3 \times 1.5 \times 3=157.9$ ( impact development of $\mathrm{AO}$ is positive).

Determination of a posteriori probability quotient (APPQ): $A P P Q=L H R \times A P R I Q=157.9 \times 0.21=33.159$.

Determination of probability for to develop or not an O.A: $\mathrm{P}=\frac{\mathrm{APPQ}}{1+\mathrm{APPQ}}$.

The mathematic model showed that, the probability for to develop an AO with: 7 factors $=0.97=97 \% ; 6$ factors $=0.90=90 \%$; 5 factors $=0.75=75 \%$; 4 factors $=0.64=64 \%$; 3 factors $=0.51=51 \% ; 2$ factors $=0.48=48 \% ; 1$ factor $=0.38=38 \%$; 0 facto $=0 \%$ (Figure 1 ). 


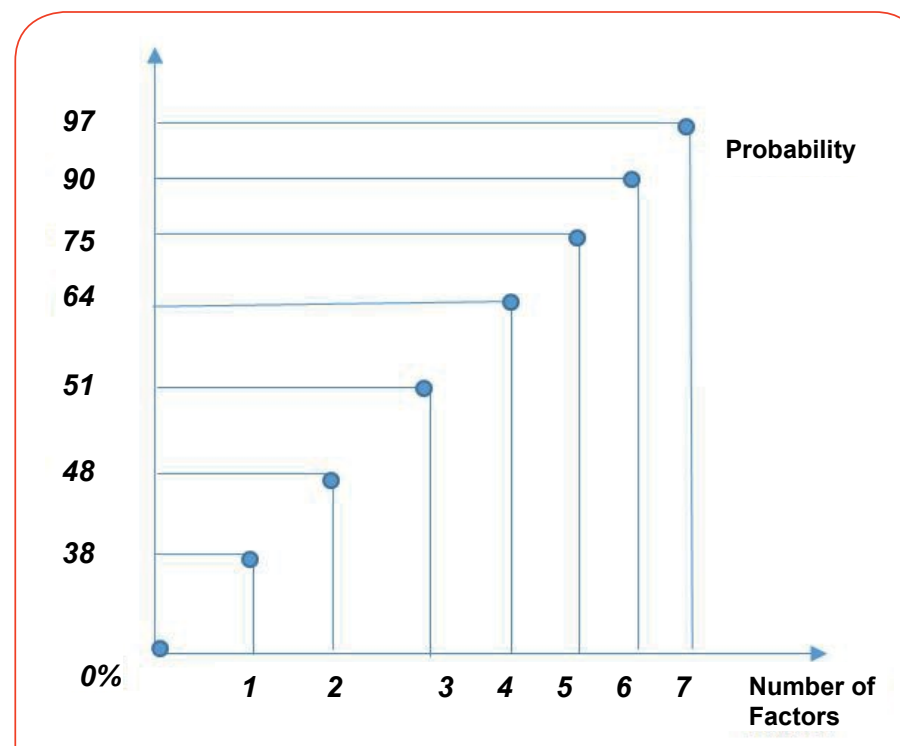

Figure 1

The probability for to develop an AO with different factors.

Validation of model: Application of SBM elaborated for to analyze the case of $A O$ designed by the experts, showed that the kappa statistics was acceptable: higher than 0.4 , indicating a likewise reason of expert. Comparison results of $A O$ provided by 8 experts with or without factors showed that le SBM predicts the occurrence of $\mathrm{AO}$ in 30 cases (75\%), and the non-occurrence of $A O$ in 10 cases (25\%). Kappa value was greater than 0.4 was accepted in consensus by the experts. Therefore, the group is considered to be homogeneous and the arithmetic mean of estimated probabilities can be used to assess the SBM.

Determination of criteria of COP (cut off point): The high value of COP from different opinions of the experts was for Sy $(93.8 \%)$, Sp (89.5\%), PPV (88.2\%), NPV (94.4\%) and OEV (19.4\%) obtained at point 0.5 .

Validation of internal SBM: Application of SBM, with the values of COP at 0.5 , compared to the consensus of experts showed that SBM predicts an occurrence of $A O$ in seven cases and no occurrence of $A O$ in the same cases confirmed by consensus of expert. The model has a good validity and performance of test of Sy $81.3 \%$, Sp $89.5 \%$ PPV $86.5 \%$, NPV $85 \%$ and OEV $85.7 \%$.

\section{Discussion}

Occurrence of $\mathrm{AO}$ in patients treated from 8 Dental clinics was determined by SBM with combination of seven factors such as $F_{3}$ : pre-operative infection $(L H R=4), F_{1}$ : poor oral dental hygiene (LHR=3 ), $F_{7}$ : postoperative infection $(L H R=3), F_{2}$ : systemic diseases with low immunity ( $L H R=1.5), F_{6}$ : inexperience of practitioner (LHR=1.5) $\mathrm{F}_{4}$ : Per operative infection (LHR=1.5), $F_{5}$ asepsis (LHR=1.3) $[5,12]$.

The likelihood ratio (LHR) of SBM value (157.9), showed that these factors had an important positive impact on the occurrence of $A O ; A P R I Q$ value (0.21) inferior to 1 , shows that the patients had less chance for to develop an $A O$. All seven risks factors of $A O$ found in the literature have been restraint by the SBM like an impact positive of $A O$ occurrence [2, 3, 5, 9, 10, 12, 24].
Once all seven risks factors are present in the patients, the probability for to develop an AO according to the SBM is more with 97 percent and that is a high risk of the patient. But once only six factors, five, four, three and two factors are presents in the patients, the risk for to develop an $A O$ is presented differently. However, the risk occurrence of $A O$ is zero if no risk factor is present. The recent result are similar from others conclusions of some studies stipule that, an association of the factors, constitute a force in the occurrence of $A O[2,3,5,9,12,24]$. Then, the correct management of postoperative complication was contribute to reduce the occurrence of $A O$ to $0.5 \%$ in the development countries [5, 12].

Prevention treatment is the most priority for to reduce the occurrence of $A O$, because can help to detect at time the modified factors of $A O$ and intervint by efficiently $[2-4,11]$. The main force of this study result an elaboration model that had grouped the numerous factors in only seven risks factors and that can render it simple usage.

In clinical situation, the sensitivity and the specificity are most often used because, the sensitivity for a damage such as AO will be based on the definition, on the characteristics and signs of this disease. In particular, it is not likely to vary from one hospital to another. The same rationale applies to the specificity because it is also based on the definition, characteristics and signs of the disease [9]. While the predictive values on the contrary, are functions of the respective proposals of patients and nonpatients in the population. These predictive values vary from one hospital to another for the same pathology; hence they are less used as evaluation parameters [9].

Limits of our study

- Different expert can produce a different a posteriori probability that can some time laid to a little low performance of SBM study.

- Was no objective measure of occurrence of AO. The occurrence was measured by opinions of experts from a consensus on the definition of occurrence and risks factors.

- We hope to have a large sample of cases of AO from numerous dental clinics than use in the study.

\section{Conclusion}

The SBM such as built can permit to calculate the probability occurrence of $A O$ in the patients that a dental extraction will be indicated for the reason that the presence or absence of one or numerous risks factors identified by experts. The Poor oral hygiene LHR3; post-operative infections LHR3, preoperative infections LHR4, were the most important identified factors predictive of the occurrence of $A O$ in our dental clinics of $D$. $R$. Congo/Kinshasa city.

The corrected of these three factors can contribute to reduce the frequency of that pathology in our population. 


\section{References}

1 Agoda P (2005) The dental extraction at the CHU in Lomé (Togo) about 981 patients from 1996 to 2001. Dév Et Sant 178: 6.

2 Badiane C (200) Alvéolectonie first line-dental surgical interest. Dakar.

3 Blondeau $F$ (2007) The extraction of mandibular third molars, postoperative complications and risk factors. JADC 73: 325a-325c.

4 Bui CH (2003) Types, frequencies, and Risk factors for complications after third molars extractions. Am Ass Oral-Max-Surg 2003: 13791389.

5 Antonia Kolokythas E (2010) Alveolar osteitis (OA), a comprehensive review of concepts and controversies. Int J Dent 2010: 249073

6 Charles H, Hennekens (1998) Epidémiologie en médecine. Edition: Frison-Rochee.

7 Pewsnera D, Bleuerb JP, Bucherc HC, Battaglia DM, Jüni $P$, et al. (2001) On the path of intuition ? Bayes theorem and diagnosis in general practice. Partie I Forum Méd Suisse Nn 3: 17.

8 Mafuta E, Mudipanu, Munyanga SM, Bwira EM (2014) Determinants of the success of income generating activities managed by a person living with HIV in Kinshasa, Democratic Republic of the Congo: a glance of congolese experiences. Ann Afr Med 7: 3.

9 Diouf A (2007) Oral biofilm and dental diseases. Antibiotiques SAS 2007: 181-188.

10 Gassama Barry (2009) The first line alvéolectoni: surgical interest in about 101 cases. Revue du COSA-CMF 16: 44.

11 Muyembi (2011) Preventing dental alveolitis postextractions the University Clinics of Kinshasa (DRC). Honors thesis in Oral Surgery, Faculty of Medicine, Kinshasa.
12 Nekson (2011) Factors associated with complications from the removal of third molars: A cross-sectional study. Méd Oral path Chir Buccal 16: E375-E380.

13 RDC (2015) Ministry of Planning: Monograph Kinshasa. Avril 2005.

14 OMS RDC (2014) Ministry of Public Health, USA places the health sector. Rapport provisoire, April-June, 1998.

15 UNDP (2014) United Nations Development Programme in the RDC. Province de Kinshasa.

16 RDC (2014) Presidency of the Republic. Director Health Development Plan. PDDS 2006-2009.

17 RDC (2014) Ministry of Public Health, General Secretariat. National health development plan, PNDS, 2011-2015.

18 OMS RDC (2014) Ministry of public health, national human resources development for health. 2011-2015.

19 UNDP (2014) UN programs for development, fight against poverty Unit. Province de Kinshasa.

20 Gustafson H, David H (1992) Systems to support health polycyanalysis. Health Administration Press, Chicago.

21 Gustagson H, David H (1993) The construction, reliability, validit, application and impact of a quality Index for spychiatric, Emergencies. Health Services Research 28: 131-158.

22 Lim SS, Vost, Vos T, Flaxman AD, Danaei G, Shibuya K, et al. (2016) A comparative Risk assessment of burden of disease and injury attributable to 67 risk factors and Risk factor clusters in 21 regions: 1990-2010. Lancet 380: 2224-2260.

23 World Health Organization (2008) The global burden of disease 2004. Geneva.

24 Engeland CG, Bosch JA, Cacioppo JT, Marucha PT (2006) Mucosal Wound Healing, The roles of Age et sex. Arch Surg 141: 1193-1197. 